\title{
Prosocial competencies among adolescent siblings of the physically disabled
}

\author{
Lidia Perenc $^{1 \cdot A, D, E}$, Mieczystaw Radochoński ${ }^{2 \cdot A, B, C, F}$, Anna Radochońska ${ }^{2 \cdot B, C, E}$ \\ 1: Medical Faculty, University of Rzeszow, Poland \\ 2: Faculty of Education, University of Rzeszow, Poland
}

\section{BACKGROUND}

The current study examined possible prosocial benefits of having a disabled sibling. Until now research has mainly focused on the negative effects of having a sibling with a disability. We hypothesized that regular and frequent interactions with a disabled person should result in an increase of positive attitude and empathy toward other people who are in a disadvantageous situation.

\section{PARTICIPANTS AND PROCEDURE}

A sample of 208 students from public secondary schools (middle and high schools) completed the Polish version of the Prosocial Tendencies Measure (PTM) in order to assess the tendencies to prosocial behaviors in different conditions. Participants were between 13 and 18 years old. Ninety-six adolescents had a disabled sibling (group T) and 112 constituted the control group (group C).

\section{RESULTS}

Results showed that group $\mathrm{T}$ generally scored higher than group $\mathrm{C}$ in the number of helping behaviors. Furthermore, girls scored higher than boys in anonymous prosocial behaviors. The older adolescents are more inclined to use helping behaviors both in anonymous and compliant situations than their younger colleagues.

\section{CONCLUSIONS}

Presence of disabled children in a family context may facilitate prosocial behavior in their non-disabled siblings. Older participants less frequently described themselves as prosocial in public situations. In contrast, younger adolescents reported weaker prosocial tendencies in anonymous and compliant situations. The effect of gender on prosocial tendencies was significant for public prosocial behavior, with a higher level achieved by males in this domain. Data analysis also showed significantly greater emotional and altruistic tendencies in females than in males.

\section{KEY WORDS}

prosocial behavior; disability; siblings; adolescents

CORRESPONDing Author - Mieczysław Radochoński, Ph.D., Faculty of Education, University of Rzeszow, 24 Jalowego Str., 35-959 Rzeszow, Poland, phone +48 1787218 16, e-mail: mieczrad@univ.rzeszow.pl Authors' CONTRiBution - A: Study design · B: Data collection · C: Statistical analysis · D: Data interpretation ·

E: Manuscript preparation · F: Literature search · G: Funds collection

TO CITE ThIS ARTICLE - Perenc, L., Radochoński, M., \& Radochońska, A. (2015). Prosocial competencies among

adolescent siblings of the physically disabled. Current Issues in Personality Psychology, 3(4), $195-202$.

RECEIVED 11.06.2015 - REVIEWED 28.07.2015 • ACCEPTED 22.08.2015 · PUBLISHED 06.09.2015 


\section{BACKGROUND}

According to research, stressful conditions in the family seem to be able to promote prosocial tendencies. For example, Midlarsky (1991) suggested that helping other people can provide a distraction from a stress situation and give a person a feeling of purposefulness. Klingman (2002) concluded that this person can then cognitively reinterpret the situation in order to increase feelings of meaning and self-worth. As a result of this reinterpretation, subsequent behaviors often focus on helping others who are in need.

Siblings not only share genetically inherited traits, but they also share a variety of interactions and transactions important for the development of social skills. Many authors have emphasized the importance of sibling relationships, and how they change during successive stages of development, but there are few studies in which social development of siblings of children with disabilities is analyzed (Zukow-Goldring, 1995). In a family where one of the children becomes chronically ill or disabled, the sibling relationships tend to be more "adult" in nature, with the healthy child acting in the dominant role (Stoneman \& Brody, 1993). In these situations the role of the non-disabled sibling is very complex, and it is affected by the family environment, which can facilitate or inhibit mutual relationships between siblings. Some researchers who have compared families with disabled and with non-disabled children have come to contradictory conclusions about the effect of healthy child responsibility and care taken on disabled siblings (Larcan \& Cuzzocrea, 2011). Others have found no important differences in psychosocial development between siblings of disabled children and their peers representing the general population (Thompson, Curtner, \& O’Rear, 2011). What is more, the results obtained in some studies have shown positive effects of living with a disabled child on healthy siblings (Phuphaibul \& Muensa, 1999; Williams, 1997).

There seems to be a dearth of empirical data related to positive aspects of having a sibling with a chronic illness or disability. Most authors generally overlook the possibility of psychosocial benefits of having a sibling with a disability. Usually they focus on negative consequences suffered by healthy children and adolescents of the disabled sister or brother. Some authors are critical towards this 'focus on pathology' (Grissom \& Borkowski, 2002), because this approach limits the scope of the researcher to assessments of pathology, excluding potential benefits. Researchers presenting this attitude continue to maintain negative presuppositions about the influence of a child with a disability on the family, despite new shifts in modern psychology. In accordance with new trends, a growing number of researchers have conducted studies to look for optimistic results related to these unique sibling relationships, such as an optimal level of assertiveness, empathy and resilience (Bellin, Bentley, \& Sawin, 2009; Jones, Welsh, Glassmire, \& Tavegia, 2006). Siblings of disabled children were characterized by maturity, responsibility and protection (Bellin \& Rice, 2009). Caplan (2011) concluded that adolescents who grew up with a sibling with a disability assessed their life as enriched by this experience. Several other studies have reported that these siblings also developed beneficial characteristics, for example, a tendency toward protection and affection, heightened independence, better cooperation, and shared decision-making and problem solving (Abrams, 2009; Bat-Chava \& Martin, 2002).

\section{AIM OF THE STUDY}

Our overall objective in the current study was to investigate whether the presence of a sibling with a disability in the family is associated with elevated prosocial tendencies in their brothers and sisters. This prediction is consistent with studies suggesting that children who grew up with siblings with disabilities present a higher level of psychosocial competencies (Bellin \& Rice, 2009; Caplan, 2011; Bat-Chava \& Martin, 2002). Additionally, this research is aimed at determining the role of age and gender as demographic variables that may be relevant in the development of psychosocial competencies in adolescents growing up in these special conditions. Since there is scarce research on this topic, we hope that our exploratory findings will help professionals to better understand the mechanisms of adjustment and social development in siblings of children with physical disabilities. When a disabled child enters the family, usually little attention is given to the sibling relationships, and most emphasis is put on the parent-child relationship. Quite often the non-disabled sibling is overlooked and no attention is paid to their relationship, when in fact the non-disabled siblings are likely to have more contact with their disabled sibling than any other person (Brown, 2003). These individuals often share the same experiences, and the mutual relationship and interactions affect their psychosocial development (Doherty, 1992). Since we found studies that indicate no significant differences in outcomes between same-gender and different-gender sibling dyads (Bat-Chava \& Martin, 2002), we decided not to measure the influence of gender within the sibling dyads, whether participants were the same or opposite gender as their disabled sibling.

\section{PARTICIPANTS AND PROCEDURE}

\section{PARTICIPANTS}

Participants were divided into two groups. The target group (Group T), aged 13 to 18 (mean age $=15.70$ 
years, $S D=1.62$ ), consisted of 96 students from public secondary schools, i.e. middle schools (gymnasium) and high schools (lyceum), located in the Rzeszow area. The selection of Group $\mathrm{T}$ was performed using purposive sampling in terms of having a physically disabled sibling. To be included in the study, the healthy adolescent and the disabled sibling had to be natural siblings and living together at home with at least one biological parent. Also, there had to be no other forms of disabilities in the family. The comparative group (Group C), aged 13 to 18 (mean age = 15.50 years, $S D=1.55)$, comprised 112 students from the same schools. The main inclusion criterion in group $\mathrm{C}$ was having at least one normally developed sibling. In this case, sibling pairs without an individual with a disability lack the psychosocial impact that the disabled/non-disabled sibling pairs have. In both groups there was a greater proportion of female than male students ( $55 \%$ vs. $45 \%$ ) (Table 1 ).

Disabled siblings were divided into groups based on medical factors: $38(39.60 \%)$ had a mobility disability, $23(23.90 \%)$ had brain injuries (e.g. cerebral palsy), $12(12.90 \%)$ were deaf, 8 (8.30\%) had visual impairment, while $15(15.30 \%)$ had multiple disabilities.

This was a cross-sectional study. After obtaining approval from the district school authority and principals of the schools, we approached 56 class groups and selected those students who met the criterion for Group T (i.e. having a physically disabled sibling). All students were told that the study was designed to assess the way teenagers think and behave in typical social situations. Students who agreed to participate were asked to take recruitment letters to their parents. After obtaining parental consent, participating students were asked to complete questionnaires during 20-minute sessions in their classrooms. Teachers were not present during completion. Student participation was voluntary and we thanked them for their participation. A similar procedure was applied in Group C, except that participants in this group were recruited by means of random sampling. No significant problems were reported during the completion of the questionnaire in both groups.

\section{INSTRUMENTS}

Participants provided basic data on their personal demographics. They also completed the Polish version of the Prosocial Tendencies Measure (PTM) (Carlo \& Randall, 2002). The PTM is a 23-item Likert-type measure of 6 prosocial tendencies: 1. Public (i.e. helping others in front of spectators, largely motivated by approval), 2. Compliant (i.e. helping others when requested to), 3. Emotional (i.e. helping others who are in an emotionally evocative situation), 4. Dire (i.e. helping in emergency situations), 5. Anonymous (i.e. helping others without their knowledge or recognition), 6. Altruistic (i.e. helping others with little regard for personal reward). Altruism items are scored reversely. Participants were asked to mark how well these items described them on a 5-point rating scale ranging from 1 ("Does not describe me") to 5 ("Describes me well"). This scale was translated and back-translated to Polish with the supervision of the third author. High scores on each scale reflected stronger endorsement.

\section{RESULTS}

The discussion of results is based on statistical analyses applying mean $(M)$, standard deviation $(S D)$ and $t$-test using the software SPSS 20 for Windows 7 . We wanted to determine differences between the studied groups on both the entire PTM scale as well

Table 1

Demographics of the participants $(N=208)$

\begin{tabular}{|c|c|c|c|c|c|c|}
\hline \multirow[t]{2}{*}{ Variable } & \multicolumn{2}{|c|}{ Group T } & \multicolumn{2}{|c|}{ Group C } & \multicolumn{2}{|c|}{ Total } \\
\hline & $n$ & $\%$ & $n$ & $\%$ & $n$ & $\%$ \\
\hline \multicolumn{7}{|l|}{ Sex } \\
\hline female & 52 & 54.20 & 62 & 55.40 & 114 & 54.80 \\
\hline male & 44 & 45.80 & 50 & 44.60 & 94 & 45.20 \\
\hline \multicolumn{7}{|l|}{ Educational level } \\
\hline lower (gymnasium) & 50 & 52.10 & 59 & 52.70 & 109 & 52.40 \\
\hline upper (lyceum) & 46 & 47.90 & 53 & 47.30 & 99 & 47.60 \\
\hline \multicolumn{7}{|l|}{ Residential area } \\
\hline urban & 85 & 88.50 & 94 & 83.90 & 179 & 86.00 \\
\hline rural & 11 & 11.50 & 18 & 16.10 & 29 & 14.00 \\
\hline
\end{tabular}


as its following subscales: 1) compliant, 2) public, 3) anonymous, 4) dire, 5) emotional, and 6) altruism. We hypothesized that adolescents having a sibling with a physical disability would score differently on the overall reported prosocial tendencies, as reflected in the scores on the PTM scale, in comparison to their peers representing the general population. The mean score across all six subscales for adolescents from group $\mathrm{T}$ was 3.12 and 2.87 for group $\mathrm{C}$ (Table 2). The difference was statistically significant at the $.050 \mathrm{sig}$ nificance level. Generally speaking, adolescents having siblings with physical disabilities reported a higher overall level of prosocial tendencies compared to their peers who do not experience frequent and regular contacts with disabled people in the family environment.

The next step of the analysis was directed at assessment of the differences between the two groups on the PTM subscales. We found statistically significant differences only in the following three subscales: anonymous, emotional and altruism. On the anonymous subscale group $\mathrm{T}$ scored higher than group $\mathrm{C}$ $(p<.050)$. Participants belonging to group $\mathrm{C}$ were less likely to report anonymous prosocial tendencies than their colleagues from group T. For emotional prosocial tendencies, there was a similar trend in the compared groups. The mean score in group $\mathrm{T}$ was 3.92 , while in group C it was $3.45(p<.010)$. The most significant difference was noted in relation to the altruism subscale scores. Adolescents from group T expressed much higher levels in altruistic prosocial tendencies than participants from group C (see Table 2). In the remaining three subscales (i.e. compliant, public and dire) differences between the two groups are not statistically significant $(p>.050)$.

Some significant differences emerged in relation to participants' level of education and their age. Students attending a middle school were 13 to 15 years old (mean 14.20), and students attending a high school were 16 to 18 (mean 17.30). Statistically speaking, those two age groups had significantly different scores on the compliant, public and anonymous subscales of the measure used in this study (see Table 3 ). We observed the largest difference between middle school (younger) and high school (older) students in the public subscale $(p<.010)$, with means of 2.23 and 1.88 respectively. The older students scored lower in public prosocial tendencies than their younger colleagues. In the remaining two subscales the differences between the compared groups were inverse. On the anonymous subscale the older students ob-

Table 2

Descriptive statistics for the PTM subscales by basic groups

\begin{tabular}{|c|c|c|c|c|c|c|}
\hline \multirow[t]{2}{*}{ PTM subscale } & \multicolumn{2}{|c|}{ Group T $(n=96)$} & \multicolumn{2}{|c|}{ Group C $(n=112)$} & \multirow[t]{2}{*}{$t$} & \multirow[t]{2}{*}{$p$} \\
\hline & $M$ & $S D$ & $M$ & $S D$ & & \\
\hline Compliant & 3.68 & 0.97 & 3.54 & 0.98 & -1.15 & n.s. \\
\hline Public & 2.08 & 0.62 & 2.14 & 0.74 & 0.94 & n.s. \\
\hline Anonymous & 2.79 & 0.87 & 2.34 & 0.65 & 3.25 & .050 \\
\hline Dire & 3.41 & 0.91 & 3.56 & 0.96 & -0.84 & n.s. \\
\hline Emotional & 3.92 & 0.95 & 3.45 & 0.89 & 6.81 & .010 \\
\hline Altruism & 2.87 & 0.78 & 2.26 & 0.73 & 8.10 & .010 \\
\hline Total & 3.12 & 0.85 & 2.87 & 0.83 & 4.19 & .010 \\
\hline
\end{tabular}

Table 3

Descriptive statistics for the PTM subscales by age

\begin{tabular}{|c|c|c|c|c|c|c|}
\hline \multirow[t]{2}{*}{ PTM subscale } & \multicolumn{2}{|c|}{$\begin{array}{l}\text { Middle school } \\
\quad(n=109)\end{array}$} & \multicolumn{2}{|c|}{$\begin{array}{l}\text { High school } \\
\quad(n=99)\end{array}$} & \multirow[t]{2}{*}{$t$} & \multirow[t]{2}{*}{$p$} \\
\hline & $M$ & $S D$ & $M$ & $S D$ & & \\
\hline Compliant & 3.49 & 0.79 & 3.74 & 0.85 & 3.51 & .050 \\
\hline Public & 2.23 & 0.71 & 1.88 & 0.56 & 6.82 & .010 \\
\hline Anonymous & 2.44 & 0.64 & 2.76 & 0.77 & -3.58 & .010 \\
\hline Dire & 3.35 & 0.95 & 3.48 & 0.95 & 0.96 & n.s. \\
\hline Emotional & 3.71 & 0.93 & 3.65 & 0.88 & -1.72 & n.s. \\
\hline Altruism & 2.58 & 0.88 & 2.49 & 0.83 & 1.25 & n.s. \\
\hline
\end{tabular}


Table 4

Descriptive statistics for the PTM subscales by gender of participants

\begin{tabular}{lllllll}
\hline PTM subscale & \multicolumn{2}{c}{ Boys $(n=94)$} & \multicolumn{2}{c}{ Girls $(n=114)$} & & \multirow{2}{*}{$p$} \\
\cline { 2 - 5 } & $M$ & $S D$ & $M$ & $S D$ & & \\
\hline Compliant & 3.57 & 0.85 & 3.64 & 0.78 & -1.65 & n.s. \\
Public & 2.26 & 0.59 & 1.82 & 0.55 & 7.12 & .010 \\
Anonymous & 2.58 & 0.71 & 2.76 & 0.69 & 1.28 & n.s. \\
Dire & 3.45 & 0.74 & 3.54 & 0.56 & 2.10 & n.s. \\
Emotional & 3.43 & 0.68 & 3.85 & 0.83 & 3.15 & .050 \\
Altruism & 2.25 & 0.72 & 2.90 & 0.67 & 6.81 & .010 \\
\hline
\end{tabular}

Table 5

Comparison of means and standard deviations with other study

\begin{tabular}{|c|c|c|c|c|c|}
\hline \multirow[t]{2}{*}{ PTM subscale } & \multicolumn{2}{|c|}{ Current study (Group T) } & \multicolumn{2}{|c|}{ Carlo \& Randall (2002) } & \multirow[t]{2}{*}{ Difference (means) } \\
\hline & M & $S D$ & $M$ & $S D$ & \\
\hline Compliant & 3.68 & 0.97 & 3.82 & 0.83 & -0.14 \\
\hline Public & 2.08 & 0.62 & 2.06 & 0.75 & +0.02 \\
\hline Anonymous & 2.79 & 0.87 & 2.77 & 0.94 & +0.02 \\
\hline Dire & 3.41 & 0.91 & 3.53 & 0.77 & -0.12 \\
\hline Emotional & 3.92 & 0.95 & 3.70 & 0.77 & +0.22 \\
\hline Altruism & 2.87 & 0.78 & 4.18 & 0.67 & -1.31 \\
\hline
\end{tabular}

tained higher scores $(M=2.76)$ than the younger ones $(M=2.44)$. In this case the difference was at the .010 significance level. Also on the compliant subscale the high school students scored higher $(M=3.74)$ than the middle school students $(M=3.49)$. This indicates that older adolescents are more inclined to use helping behaviors both in anonymous and compliant situations than their younger colleagues. Controversially, scores on the altruism and public subscales decreased with age, although in the case of the public subscale the difference was not significant.

Significant differences were also noted in relation to the participants' gender. There was a gender effect on the public, emotional and altruism subscales. Table 4 reports tests of differences in PTM subscales between genders. The mean values in the female group ranged from 1.82 (public) to 3.85 (emotional). The means for the male group ranged from 2.26 (public) to 3.57 (compliant). The boys showed higher levels in the public prosocial behaviors than girls $(p<.010)$. Girls reported a much higher level of altruism than boys (means are 2.90 to 2.25 respectively). The effect of gender on prosocial tendencies was also significant on the emotional subscale. The difference between girls $(M=3.85)$ and boys $(M=3.43)$ was statistically significant at the $95 \%$ probability level.
Table 5 presents the means and standard deviations of the PTM subscales used in this study compared to the means and standard deviations obtained in other research that assessed the adolescent population with these measures (Carlo \& Randall, 2002). In this case, no statistical analysis was performed to determine whether significant differences existed between the means and standard deviations from both studies. However, there is one observable difference related to the altruism subscale: Polish participants reported a much weaker tendency to help others for altruistic motives.

\section{DISCUSSION}

Studies into the effects of living and growing up with a brother or sister with a physical disability for the healthy child are inconclusive. Some studies on this subject have been conducted worldwide, but only a few studies were conducted in Poland. Our study compared the prosocial tendencies in adolescent siblings of children with a physical disability and siblings of non-disabled children. Living with a physically disabled or chronically ill child is a difficult experience for all family members. The most significant sources of stress experienced by parents of these 
children are the permanency of the condition and the disapproval of the child's behavior demonstrated by society and other family members (Pisula, 2007).

Most of the past studies focusing on disabled children and their families have extended to parents, but have not examined fully the effects of having a disabled sibling on the psychosocial development of healthy children and adolescents. Sibling relationships in families with children with disabilities are complex and may be mediated by a number of variables. Crnic and Leconte (1986) suggest that caretaking responsibilities, age, birth order, individual temperament, socioeconomic status, and severity of disability may determine whether healthy siblings are negatively or positively affected by the presence of sibling with disabilities.

The literature suggests that the impact of physical disability on psychosocial development of non-disabled siblings may also depend on the informant. For example, mothers usually view the impact of disability more negatively as compared to siblings. It is interesting that when standardized measures were used to assess the impact of disability on healthy children, there was little difference between the siblings of physically disabled children and control groups (Dew, Balandin, \& Llewellyn, 2008).

Our findings suggest that positive psychosocial outcomes may be associated with chronic stress resulting from the presence of a disabled child in the family. As predicted, the results of our study show evidence of higher levels of overall prosocial tendencies in siblings of children with a physical disability than in their peers having a non-disabled sibling. This is consistent with the results of other studies. For example, Seligman and Darling (1997) found that children who are actively involved in caring for a child with a disability tend to be socially well-adjusted despite the added responsibilities. Also such siblings report that they developed greater understanding of other people in general and the disabled in particular, more compassion and more appreciation of their own good health (Meyer, 1993). Healthy children can often teach their disabled siblings some skills which could not be copied from their parents. Quite often they are forced to act as a substitute parent, and this gives them the opportunity to feel satisfaction from their successes related to this role. Watching the disabled sibling while struggling to learn skills that are easy for themselves, the non-disabled adolescents learn greater respect for the disabled in general and they learn ways to overcome difficulties occurring in their own lives.

Because of inconsistent data, it was difficult to predict whether there would be an increase or a decrease in the level of prosocial behavior between subjects belonging to earlier and later phases of adolescence. In other words, the findings regarding age-related trends in prosocial development during adolescence are less clear than those observable during childhood
(Fabes, Carlo, Kupanoff, \& Laible, 1999). It also means that relations between age and prosocial behavior vary depending on the characteristics of studies, such as type of social group, and methods used in research. In this study the older participants (i.e. high school students) exhibited a decrease in public prosocial behaviors. This decline might be a result of an increasing concern and attention to one's own needs and personal problems typical of late adolescence. A positive finding of this study relates to the increase in anonymous and compliant prosocial tendencies in the group of older adolescents. Taken together, these differences might result from different developmental trajectories of particular prosocial behaviors during adolescence. The compared groups did not have significantly different scores on the dire, emotional and altruism subscales. This result is somewhat surprising in relation to the behaviors motivated by altruistic tendencies. According to psychodynamic theory, altruistic behavior is governed by a mature defense mechanisms (Whitty, 2003). From this point of view, altruism can be seen as a higher order form of prosocial behavior than the other forms. However, older adolescents participating in this study did not differ in their sensitivity to altruistic motives when compared to their younger colleagues.

Our study also revealed an effect of participants' gender. Higher levels of public prosocial behavior were reported for males than for females. On the other hand, females reported higher levels of emotional and altruistic prosocial behaviors. There were no significant gender differences found for compliant, dire and anonymous prosocial behaviors. These findings are congruent with research performed by Hardy and Carlo (2005) on a group of 142 high school students (mean age $=16.80$ ). Also in some previously conducted studies, researchers reported moderately strong gender differences in prosocial behaviors, in that adolescent girls exhibited higher levels of prosocial traits and behaviors than adolescent boys (Carlo, Koller, Eisenberg, De Silva, \& Frohlich, 1996; Eisenberg, Miller, Shell, McNalley, \& Shea, 1991). Other research findings related to gender differences in prosocial behaviors indicate that females tend to engage more often in emotional, altruistic and compliant prosocial behaviors than males, mainly because they are more empathetic. On the other hand, males are prone to engage more readily in public prosocial behaviors (McGinley \& Carlo, 2007). As with the controversy surrounding the gender effect, in a more recent study Eagly (2009) found that although men and women did not differ in the levels of involvement in prosocial behaviors, they are different in the way of preference of particular categories of these actions. Similar observations came from longitudinal studies examining the role of psychological factors determining gender differences in adolescents (Mestre et al., 2009). 


\section{LIMITATIONS OF THIS STUDY}

There are some limitations related to the present study. Firstly, the sample was relatively homogeneous with respect to social background, because the vast majority of participants came from an urban milieu. Secondly, the measure used in this study was of the self-report type, which might result in self-presentation bias. Despite these reservations, the present study provided evidence that the PTM is an instrument that can successfully be used with early and late adolescents from Poland.

\section{CONCLUSIONS}

The results of the present study suggest that the presence of a disabled child in the family context may facilitate prosocial behaviors in their non-disabled siblings. However, we warn against oversimplifying this main conclusion. Firstly, it is obvious that multiple factors are involved in facilitating prosocial behavior in adolescents, for example parenting styles, gender or situational influences. Secondly, it is feasible that some adolescents might have other motives for their prosocial actions, such as pressure of a wider social milieu, or fear of the consequences of not being helpful.

The present findings showed a moderate relationship between age and specific prosocial tendencies. Older participants described themselves as prosocial in public situations less frequently than the younger ones. In contrast, younger adolescents reported weaker prosocial tendencies in anonymous and compliant situations.

The effect of gender on prosocial tendencies was significant for the public prosocial behavior, with a higher level achieved by males in this domain. Data analysis also revealed significantly greater emotional and altruistic tendencies in females than in males.

Specifically, this study underlines the importance of including brothers and sisters of disabled children in family interventions and in treatment planning related to the affected child. It also supports the assertion that future studies on this topic should include multiple respondents and should examine the role of various demographic characteristics such as socio-economic status, religion, marital status, gender of the disabled child, etc. Some research problems cannot be adequately resolved until longitudinal studies are conducted.

\section{ACKNOWLEDGMENTS}

The authors appreciate the assistance and cooperation of the Rzeszow District Education Authority, school staff, teachers and students.

\section{RefERENCES}

Abrams, M. S. (2009). The well sibling: Challenges and possibilities. American Journal of Psychotherapy, 63, 305-317.

Bat-Chava, Y., \& Martin, D. (2002). Sibling relationships for deaf children: The impact of child and family characteristics. Rehabilitation Psychology, 47, 73-91.

Bellin, M. H., Bentley, K. J., \& Sawin, K. J. (2009). Factors associated with the psychological and behavioral adjustment of siblings of youths with spina bifida. Families, Systems, \& Health, 27, 1-15.

Bellin, M. H., \& Rice, K. M. (2009). Individual, family, and peer factors associated with the quality of sibling relationships in families of youths with spina bifida. Journal of Family Psychology, 23, 39-47.

Brown, E. (2003). Loss Change and Grief. London: David Fulton.

Caplan, R. (2011). Someone else can use this time more than me: Working with college students with impaired siblings. Journal of College Student Psychotherapy, 25, 120-131.

Carlo, G., Koller, S. H., Eisenberg, N., Da Silva, M. S., \& Frohlich, C. B. (1996). Across-national study on the relations among prosocial moral reasoning, gender role orientations, and prosocial behaviors. Developmental Psychology, 32, 231-240.

Carlo, G., \& Randall, B. A. (2002). The development of a measure of prosocial behaviours for late adolescents. Journal of Youth and Adolescence, 31, 31-44.

Crnic, K. A., \& Leconte, J. M. (1986). Understanding sibling needs and influences. In: R. R. Fewell, \& P. F. Vadasy (eds.), Families of handicapped children. Austin, Texas: Pro-Ed.

Dew, A., Balandin, S., \& Llewellyn, G. (2008). The Psychosocial Impact on Siblings of People with Lifelong Physical Disability: A Review of the Literature. Journal of Developmental and Physical Disabilities, 20, 485-507.

Doherty, J. (1992). A sibling remembers. Candlelighters Childhood Cancer Foundation Quarterly Newsletter, 16, 14-16.

Eagly, A. H. (2009). The His and Hers of prosocial behavior: An examination of the social psychology of gender. American Psychologist, 64, 644-658.

Eisenberg, N., Miller, P. A., Shell, R., McNalley, S., \& Shea, C. L. (1991). Prosocial development in adolescence: A longitudinal study. Developmental Psychology, 27, 849-857.

Fabes, R. A., Carlo, G., Kupanoff, K., \& Laible, D. (1999). Early adolescence and prosocial/moral behavior I: The role of individual processes. Journal of Early Adolescence, 19, 5-16.

Grissom, M. O., \& Borkowski, J. G. (2002). Self-efficacy in adolescents who have siblings with or without disabilities. American Journal on Mental Retardation, 107, 79-90. 
Hardy, S. A., \& Carlo, G. (2005). Religiosity and prosocial behaviours in adolescence: the mediating role of prosocial values. Journal of Moral Education, 34, 231-249.

Jones, K. B., Welsh, R. K., Glassmire, D. M., \& Tavegia, B. D. (2006). Psychological functioning in siblings of children with attention deficit hyperactivity disorder. Journal of Child and Family Studies, 15, 753-759.

Klingman, A. (2002). Children under stress of war. In: A. M. La Greca, W. K. Silverman, E. M. Vernberg, \& M. C. Roberts (eds.), Helping children cope with disasters and terrorism (pp. 359-380). Washington, DC: American Psychological Association.

Larcan, R., \& Cuzzocrea, F. (2011). Funzionamento della famiglia e sviluppo psico-sociale dei fratelli di individui con disabilità intellettive [Family functioning and psycho-social development of the brothers of individuals with intellectual disabilities]. Psicologia Clinica dello Sviluppo, 15, 123-153.

McGinley, M., \& Carlo, G. (2007). Two sides of the same coin: The relations between prosocial and physically aggressive behaviours. Journal of Youth and Adolescence, 36, 337-349.

Mestre, M. V., Samper, P., Frias, M. D., \& Tur, A. M. (2009). Are women more empathetic? A longitudinal study in adolescence. The Spanish Journal of Psychology, 12, 76-83.

Meyer, D. J. (1993). Lessons learned: Cognitive coping strategies of overlooked family members. In: A. P. Turnbull, J. M. Patterson, S. K. Behr, D. L. Murphy, J. G. Marquis, \& M. J. Blue-Banning (eds.), Cognitive coping, families and disability (pp. 81-93). Baltimore, MD: Paul H. Brookes.

Midlarsky, E. (1991). Helping as coping. In: M. S. Clark (ed.), Prosocial behavior (pp. 238-264). Newbury Park, CA: Sage Publications.

Pisula, E. (2007). A comparative study of stress profiles in mothers of children with autism and those of children with Down's syndrome. Journal of Applied Research in Intellectual Disabilities, 20, 274278.

Phuphaibul, R., \& Muensa, W. (1999). Negative and positive adaptive behaviors of Thai school-aged children who have a sibling with cancer. Journal of Pediatric Nursing, 14, 342-348.

Seligman, M., \& Darling, R. B. (1997). Ordinary families; special children: A systems approach to childhood disability ( $2^{\text {nd }}$ ed.). New York: Guilford.

Stoneman, Z., \& Brody, G. H. (1993). Sibling relations in the family context. In: Z. Stoneman, P. W. Berman (eds.), The effects of mental retardation, disability and illness (pp. 3-30). Baltimore, MD: Brookes.

Thompson, A. B., Curtner, M. E., \& O’Rear, M. R. (1994). The psychosocial adjustment of well sib- lings of chronically ill children. Children's Health Care, 23, 211-226.

Whitty, M. T. (2003). Coping and defending: Age differences in maturity of defense mechanisms and coping strategies. Aging \& Mental Health, 7, 123.

Williams, P. D. (1997). Siblings and pediatric chronic illness: A review of the literature. International Journal of Nursing Studies, 34, 312-323.

Zukow-Goldring, P. (1995). Sibling caregiving. In: M. H. Bornstein (ed.), Handbook of parenting. Biology and ecology of parenting (vol. 2, pp. 177-208). Mahwah, NJ: Erlbaum. 